\title{
DEPARTMENT OF COMMERCE.
} BUREAU OF STANDARDS.

\author{
CIRCULAR OF THE BUREAU OF STANDARDS.
}

No. 98.

[Second edition. Issued February 28, 1923.]

\section{UNITED STATES GOVERNMENT SPECIFICATION FOR VOLATILE MINERAL SPIRITS FOR THINNING PAINTS. ${ }^{1}$}

\section{FEDERAL SPECIFICATIONS BOARD. \\ STANDARD SPECIFICATION No. 16.}

[Revised January 2, 1923.]

This specification was officially adopted by the Federal Specifications Board on February 3, 1922, for the use of the departments and independent establishments of the Government in the purchase of volatile mineral spirits for thinning paints.

CONTENTS.

I. General...............

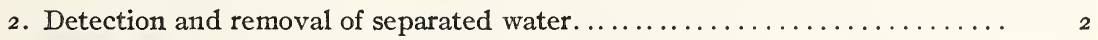

3. Sampling . . . . . . . . . . . . . . . . . .

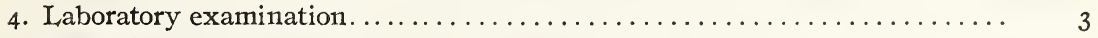

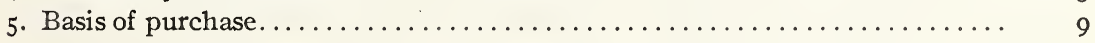

\section{GENERAL.}

This specification applies only to petroleum distillates, known as mineral spirits. The material delivered under this specification shall conform to the following requirements:

APPEARANCE.-Shall be clear and free from suspended matter and water.

CoLOR.-Shall be no darker than an aqueous solution of potassium dichromate containing $0.0048 \mathrm{~g}$ per liter (this corresponds to No. 2I Saybolt chromometer).

SPOT TEST.-Shall evaporate completely from filter paper.

1 The mineral spirits called for in this specification is the same as that called for in Specifications for Petroleum Products, Bureau of Mines Technical Paper 323.

$27818^{\circ}-23$ 
FLASH PoInT.-Shall be not lower than $30^{\circ} \mathrm{C} .\left(86^{\circ} \mathrm{F}\right.$.) when tested in a closed cup tester.

BLACKENING.-Shall not blacken clean metallic copper. Distillate below $130^{\circ} \mathrm{C} .\left(266^{\circ} \mathrm{F}\right.$.) shall not exceed 5 per cent. Distillate below $230^{\circ} \mathrm{C}$. $\left(446^{\circ} \mathrm{F}\right.$.) shall be not less than 97 per cent.

AcIDITY.-Shall be neutral.

\section{DETECTION AND REMOVAL OF SEPARATED WATER.}

Draw a portion by means of a glass or metal container with a removable stopper or top, or with a "thief," from the lowest part of the container, or by opening the bottom valve of the perfectly level tank car. If water is found to be present, draw it all out, record the quantity, and deduct it from the total volume of liquid delivered.

NotE.-Deliveries will in general be sampled and tested by the following methods, but the purchaser reserves the right to use any additional available information to ascertain whether the material meets the specification.

\section{SAMPLING.}

The method of sampling given under $(a)$ should be used whenever feasible. When method $(a)$ is not applicable, method (b), $(c)$, or $(d)$ is to be used, according to the special conditions that obtain.

(a) While Loading Tank Car or While Filling Containers FOR SHIPMENT.- Samples shall be drawn by the purchaser's inspector at the discharge pipe where it enters the receiving vessel or vessels. The composite sample shall be not less than 5 gallons and shall consist of small portions of not more than I quart each taken at regular intervals during the entire period of loading or filling. The composite sample thus obtained shall be thoroughly mixed, and from it three samples of not less than I quart each shall be placed in clean, dry glass bottles or tin cans, which must be nearly filled with the sample and securely stoppered with new clean corks or well-fitting covers or caps. These shall be sealed and distinctly labeled by the inspector. One shall be delivered to the buyer, one to the seller, and the third held for check in case of dispute.

(b) From Loaded Tank Car or Other Large Vessel.-The composite sample taken shall be not less than 5 gallons and shall consist of numerous small samples of not more than I quart each taken from the top, bottom, and intermediate points by means of a metal or glass container with removable stopper or top. 
This device attached to a suitable pole is lowered to the various desired depths, when the stopper or top is removed and the container allowed to fill. The sample thus obtained is handled as in $(a)$.

(c) BARRELs And Drums.-Barrels and drums shall be sampled after gauging contents. Five per cent of the packages in any shipment or delivery shall be represented in the sample. Thoroughly mix the contents of each barrel to be sampled by stirring with a clean rod and withdraw a portion from about the center by means of a "thief" or other sampling device. The composite sample thus obtained shall be not less than 3 quarts, shall consist of equal portions of not less than one-half pint from each package sampled, and shall be handled as in $(a)$. Should the inspector suspect adulteration, he shall draw the samples from the suspected packages.

(d) Small Containers, Cans, etc., of io Gallons or Less.These should be sampled, while filling, by method (a) whenever possible; but in case this is impossible, the composite sample taken shall be not less than 3 quarts. This shall be drawn from at least five packages (from all when fewer), and in no case from less than 2 per cent of the packages. The composite sample thus taken shall be thoroughly mixed and subdivided as in $(a)$.

\section{LABORATORY EXAMINATION.}

(a) Appearance.-Examine to determine compliance with the specification.

(b) CozOR.-Compare in any suitable apparatus the depth of color of the sample with the depth of color of a fresh solution of potassium dichromate in distilled water containing $0.0048 \mathrm{~g} \mathrm{~K}_{2} \mathrm{Cr}_{2} \mathrm{O}_{7}$ per liter. (If desired, the color may be determined in a Saybolt chromometer, in which case the color must be no darker than No. 2 I on that scale.)

(c) Spot Test.-Transfer five drops of the mineral spirits by means of a small pipette or burette to the center of a clean white filter paper supported on a 7 -cm crystallizing dish and allow the liquid to evaporate at room temperature, away from direct sunlight. There should be no oily spot left after 30 minutes.

(d) Flash PoInT.-Determine with either the "Tag" or Elliott closed-cup tester. The former is preferred. ${ }^{2}$

2 Directions for using the "Tag" tester may be found in A. S. T. M. Standards D56-21 and in Bureau of Mines Technical Paper No.323. Directionsfor using the Elliott cup may be found in Proceedings A. S. T. M., 1917, pt. 1, p. 414. 
(e) Blackening.-Place a clean strip of mechanically polished pure sheet copper, about $1 / 2$ inch wide and 3 inches long $(1.3 \mathrm{~cm}$ by $7.5 \mathrm{~cm})$ in a glass test tube about $3 / 4$ inch wide and 18 inches long ( 1.9 by $46 \mathrm{~cm}$ ). Add sufficient of the sample to be tested to completely cover the strip and heat rapidly to its boiling point (it is most convenient to heat the tube by immersion in an oil bath maintained at a temperature slightly higher than the initial boiling point of the mineral spirits). Keep the sample at its boiling point, without any actual distillation taking place, for 30 minutes and then examine the copper strip for blackening. A slight tarnish shall be disregarded, but any marked blackening shall be cause for rejection.

(f) Distillation.-Use the A. S. T. M. (D 86-2I T) method as described below, except that it will be necessary to read the volume of the distillate at $130^{\circ} \mathrm{C}$. and at $230^{\circ} \mathrm{C}$. and the distillation need not be carried beyond the $230^{\circ} \mathrm{C}$. $\left(446^{\circ} \mathrm{F}\right.$.) point.

\section{APPARATUS.}

Flask.-The standard roo cc Engler flask is shown in Figure r, the dimensions and allowable tolerance being as follows:

Dimensions of Engler flask.

\begin{tabular}{|c|c|c|c|}
\hline Description. & $\begin{array}{l}\text { Centi- } \\
\text { meters. }\end{array}$ & Inches. & $\begin{array}{l}\text { Toler- } \\
\text { ances } \\
\text { (cm). }\end{array}$ \\
\hline 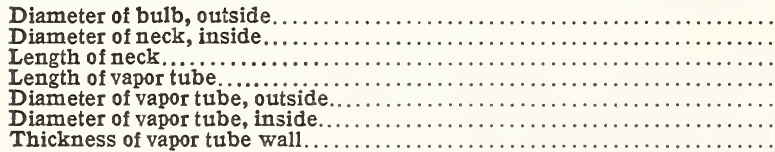 & $\begin{array}{r}6.5 \\
1.6 \\
15.0 \\
10.0 \\
.6 \\
.4 \\
.1\end{array}$ & $\begin{array}{r}2.56 \\
.63 \\
5.91 \\
3.94 \\
.24 \\
.16 \\
.04\end{array}$ & $\begin{array}{l}0.2 \\
. \frac{1}{4} \\
.3 \\
.05 \\
.05 \\
.05\end{array}$ \\
\hline
\end{tabular}

The position of the vapor tube shall be $9 \mathrm{~cm}$ ( 3.55 inches) $\pm 3 \mathrm{~mm}$ above the surface of the liquid when the flask contains its charge of $100 \mathrm{cc}$. The tube is approximately in the middle of the neck and set at an angle of $75^{\circ}$ (tolerance $\pm 3^{\circ}$ ) with the vertical.

Condenser.-The condenser (Fig. 2) consists of a 9/16 inch OD No. 20 Stubbs gauge seamless brass tube 22 inches long. It is set at an angle of $75^{\circ}$ from the perpendicular and is surrounded with a cooling bath $\mathrm{I}_{5}$ inches long, approximately 4 inches wide by 6 inches high. The lower end of the condenser tube is cut off at an acute angle and curved downward for a length of 3 inches and slightly backward, so as to insure contact with 
the wall of the graduate at a point I to $I / / 4$ inches below the top of the graduate when it is in position to receive the distillate.

Shield.-The shield (Fig. 2) is made of approximately 22gauge sheet metal and is I 9 inches high, I I inches long, and 8 inches wide, with a door on one narrow side, with two openings, $\mathrm{I}$ inch in

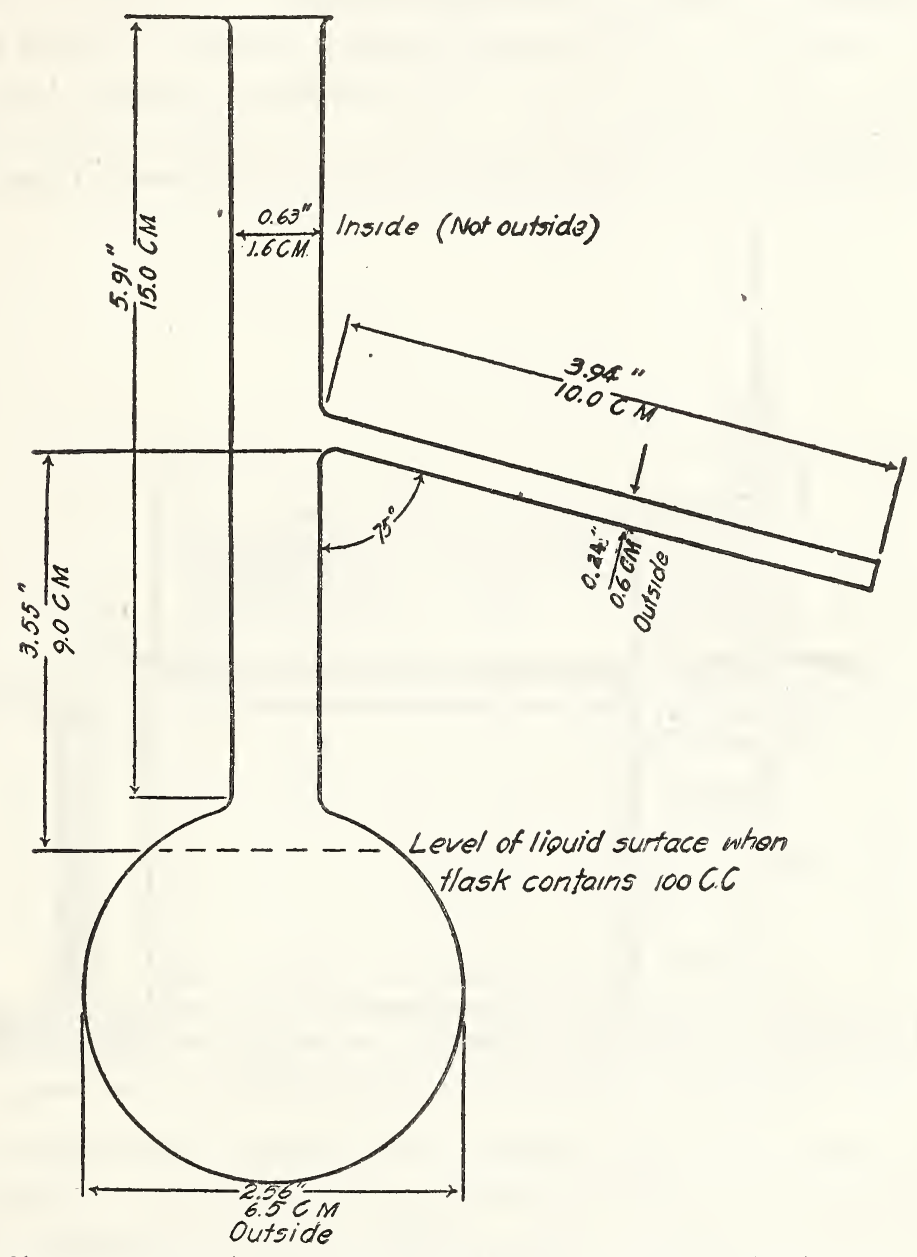

FIG. I.-Standard Ioo cc Engler flask for use in making distillation tests.

diameter, equally spaced, in each of the two narrow sides, and with a slot cut in one side for the vapor tube. The centers of these four openings are $81 / 2$ inches below the top of the shield. There are also three $\mathrm{I} / 2$-inch holes in each of the four sides, with their centers I inch above the base of the shield.

Ring support and hard asbestos boards. - The ring support is of the ordinary laboratory type, 4 inches or larger in diameter, and is

$27818^{\circ}-23-2$ 
supported on a stand inside the shield. There are two hard asbestos boards, one 6 by 6 by $1 / 4$ inch, with a hole $1 / 2$ inches in diameter in its center, the sides of which shall be perpendicular to the surface; the other, an asbestos board to fit tightly inside the shield, with an opening 4 inches in diameter concentric with the ring support. These are arranged as follows: The second asbestos board is placed on the ring and the first or smaller asbestos board on top, so that it may be moved in accordance with the directions for placing the distilling flask. Direct heat is applied to the flask only through the $I / 2$-inch opening in the first asbestos board.

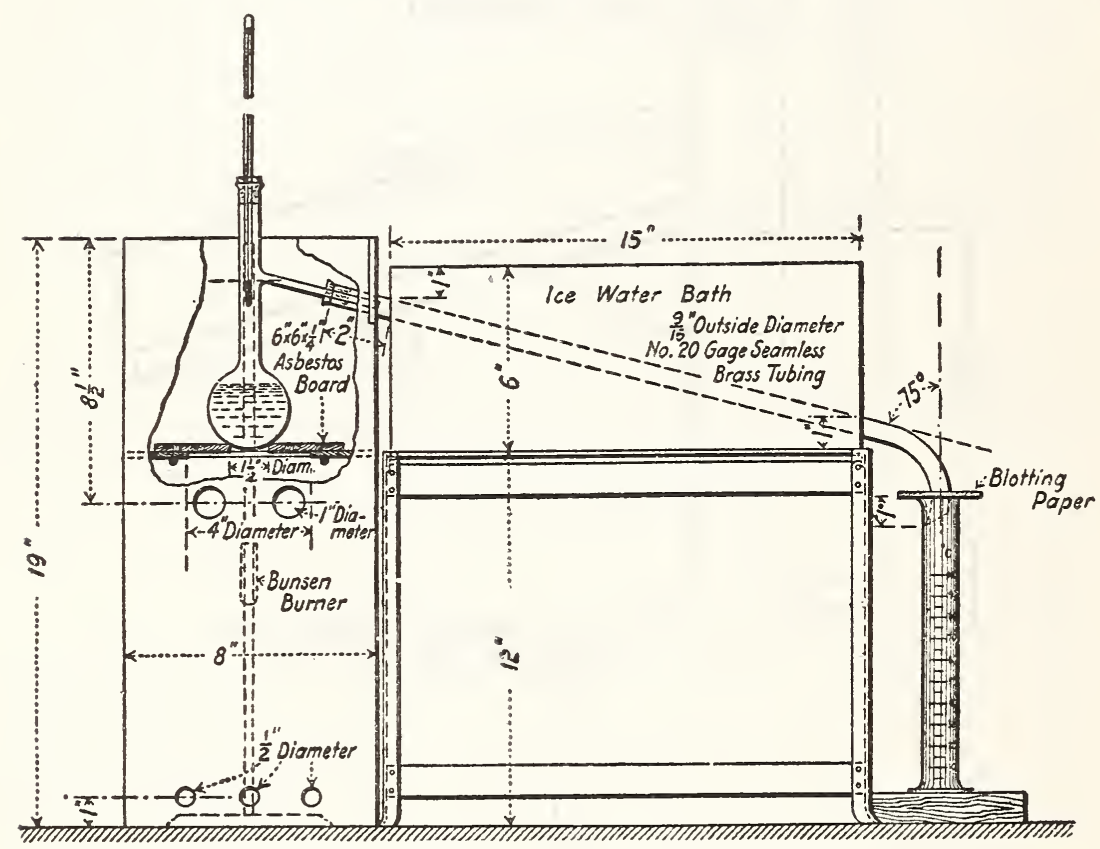

FIG. 2.-Distillation outfit (A.S. T. M.) arranged for use of gas burner.

Gas burner or electric heater.-Gas burner: The burner is so constructed that sufficient heat can be obtained to distill the product at the uniform rate specified below. The flame should never be so large that it spreads over a circle of diameter greater than $3 \frac{1}{2}$ inches on the under surface of the asbestos board. A sensitive regulating valve is a necessary adjunct, as it gives complete control of heating.

Electric heater: The electric heater, which may be used in place of the gas flame, shall be capable of bringing over the first drop within the time specified below when started cold and of continuing the distillation at the uniform rate. The electric heater 
shall be fitted with an asbestos board top $1 / 3$ to $1 / 4$ inch thick, having a hole $I \mathrm{I} / 2$ inches in diameter in the center. When an electric heater is employed, the portion of the shield above the asbestos board shall be the same as with the gas burner, but the part below may be omitted.

Thermometer.-A. S. T. M. high-distillation thermometer shall conform to the following specifications:

Type: Etched stem glass.

Total length: $38 \mathrm{rmm}$.

Stem: Plain front, enamel back, suitable thermometer tubing; diameter, 6 to $7 \mathrm{~mm}$.

Bulb: Corning normal, Jena I6 III, or equally suitable thermometric glass; length, Io to $15 \mathrm{~mm}$; diameter, 5 to $6 \mathrm{~mm}$.

Actuating liquid: Mercury.

Range: 30 to $760^{\circ} \mathrm{F}$., or o to $400^{\circ} \mathrm{C}$.

Immersion: Total.

Distance to $30^{\circ} \mathrm{F}$., or $0^{\circ} \mathrm{C}$. mark from bottom of bulb: 25 to $35 \mathrm{~mm}$.

Distance to $760^{\circ} \mathrm{F}$, or $400^{\circ} \mathrm{C}$. mark from top of tube: 30 to $45 \mathrm{~mm}$.

Filled: Nitrogen gas.

Top finish: Glass ring.

Graduation: All lines, figures, and letters clear cut and distinct; scale graduated in $2^{\circ} \mathrm{F}$. or $\mathrm{I}^{\circ} \mathrm{C}$. divisions and numbered every $20^{\circ} \mathrm{F}$. or $10^{\circ} \mathrm{C}$., the first and each succeeding $10^{\circ} \mathrm{F} .\left(5^{\circ} \mathrm{C}\right.$.) to be longer than the others.

Special markings: A. S. T. M. High Distillation, serial number, and manufacturer's name or trade-mark etched on the stem.

Accuracy: Error at any point on scale shall not exceed one smallest scale division up to $700^{\circ} \mathrm{F}$. or $370^{\circ} \mathrm{C}$.

Tests for permanency of range: After being subjected to a temperature of $700^{\circ} \mathrm{F}$. or $370^{\circ} \mathrm{C}$. for 24 hours the accuracy shall be within the limit specified.

Points to be tested for certification: $32^{\circ}, 212^{\circ}, 400^{\circ}, 700^{\circ} \mathrm{F}$. or $0^{\circ}, 100^{\circ}, 200^{\circ}, 370^{\circ} \mathrm{C}$.

Graduate.-The graduate shall be of the cylindrical type, of uniform diameter, with a pressed or molded base and a lipped top. The cylinder shall be graduated to contain Ioo $\mathrm{cc}$ and the graduated portion shall be not less than 7 inches nor more than 8 inches long. It shall be graduated in single cubic centimeters, and each fifth mark shall be distinguished by a longer line. It shall be numbered from the bottom up at intervals of $10 \mathrm{cc}$. The distance from the $100 \mathrm{cc}$ mark to the rim shall be not less than $\mathrm{I} / 4$ inches nor more than $\mathrm{I} 3 / 4$ inches. The graduations shall not be in error by more than I cc at any point on the scale.

\section{PROCEDURE.}

The condenser bath shall be filled with cracked ice ${ }^{3}$ and enough water added to cover the condenser tube. The temperature shall be maintained between 32 and $40^{\circ} \mathrm{F}$. (o and $4.5^{\circ} \mathrm{C}$.).

\footnotetext{
Any other convenient cooling medium may be used.
} 
The condenser tube shall be swabbed to remove any liquid remaining from the previous test. A piece of soft cloth attached to a cord or copper wire may be used for this purpose.

The bulb of the distillation thermometer shall be covered uniformly with a long-fiber absorbent cotton weighing not less than 3 nor more than $5 \mathrm{mg}$. A fresh portion of clean cotton shall be used for each distillation.

One hundred cubic centimeters of the product shall be measured in the Ioo $\mathrm{cc}$ graduated cylinder at 55 to $65^{\circ} \mathrm{F}$. (I 2.8 to I8. $3^{\circ}$ C.) and transferred directly to the Engler flask. None of the liquid shall be permitted to flow into the vapor tube.

The thermometer provided with a cork shall be fitted tightly into the flask, so that it will be in the middle of the neck and so that the lower end of the capillary tube is on a level with the inside of the bottom of the vapor outlet tube at its junction with the neck of the flask.

The charged flask shall be placed in the $1 \mathrm{I} / 2$-inch opening in the 6 by 6 inch asbestos board, with the vapor outlet tube inserted into the condenser tube. A tight connection may be made by means of a cork through which the vapor tube passes. The position of the flask shall be so adjusted that the vapor tube extends into the condenser tube not less than I inch nor more than 2 inches.

The graduated cylinder used in measuring the charge shall be placed, without drying, at the outlet of the condenser tube in such a position that the condenser tube shall extend into the graduate at least I inch but not below the $100 \mathrm{cc}$ mark. Unless the temperature is between 55 and $65^{\circ} \mathrm{F}$. ( 12.8 and $18.3^{\circ} \mathrm{C}$.) the receiving graduate shall be immersed up to the roo cc mark in a transparent bath maintained between these temperatures. The top of the graduate shall be covered closely during the distillation with a piece of blotting paper or its equivalent cut so as to fit the condenser tube tightly.

When everything is in readiness, heat shall be applied at a uniform rate, so regulated that the first drop of condensate falls from the condenser in not less than 5 nor more than io minutes. When the first drop falls from the end of the condenser, the reading of the distillation thermometer shall be recorded as the initial boiling point. The receiving cylinder shall then be moved so that the end of the condenser tube shall touch the side of the cylinder. The heat shall then be so regulated that the distillation will proceed at a uniform rate of not less than 4 nor more 
than $5 \mathrm{cc}$ per minute. The reading of the distillation thermometer shall be recorded when the level of the distillate reaches each Io cc mark on the graduate. After the 90 per cent point has been recorded, the heat may be increased because of the presence of the heavy ends which have high boiling points. However, no further increase of heat should be applied after this adjustment. The 4 to $5 \mathrm{cc}$ rate can rarely be maintained from the 90 per cent point to the end of the distillation, but in no case should the period between the 90 per cent and the end point be more than five minutes.

The heating shall be continued until the mercury reaches a maximum and starts to fall consistently. The highest temperature observed on the distillation thermometer shall be recorded as the maximum temperature or end point. Usually this point will be reached after the bottom of the flask has become dry. The total volume of the distillate collected in the receiving graduate shall be recorded as the recovery. The cooled residue shall be poured from the flask into a small cylinder graduated in $0 . \mathrm{I} \mathrm{cc}$, measured when cool and the volume recorded as residue. The difference between IoO $\mathrm{cc}$ and the sum of the recovery and the residue shall be calculated and recorded as distillation loss.

(g) Acidiry.-Collect in a test tube the cooled residue from the distillation flask (see $(f)$ ), add three volumes of distilled water and shake the tube thoroughly. Allow the mixture to separate and remove the aqueous layer to a clean test tube by means of a pipette. Add one drop of a I per cent solution of methyl orange. No pink or red color should be formed.

\section{BASIS OF PURCHASE.}

(a) UNIT.-Mineral spirits shall be purchased either (I) by volume, the unit being a gallon of $23 \mathrm{I}$ cubic inches at $15.5^{\circ} \mathrm{C}$. $\left(60^{\circ} \mathrm{F}\right.$.), or (2) by weight. A gallon of mineral spirits at $15.5^{\circ} \mathrm{C}$. $\left(60^{\circ} \mathrm{F}\right.$.) weighs 6.3 to 6.8 pounds. The exact weight in pounds per gallon of any sample can be determined by multiplying the specific gravity at $15.5 / 15.5^{\circ} \mathrm{C}$. $\left(60 / 60^{\circ} \mathrm{F}\right.$.) by 8.33 . ExampleIf the specific gravity at $15.5^{\circ} \mathrm{C}$. is 0.7642 , the weight per gallon at this temperature will be $0.7642 \times 8.33=6.366$ pounds. When purchased by weight, quotations shall be by the pound or by the Ioo pounds. The request for bids will state whether quotations shall be by the gallon, pound, or roo pounds.

(b) Correction of Volume.-The gallonage paid for shall be the volume corrected to a standard temperature of $15.5^{\circ} \mathrm{C}$. 
$\left(60^{\circ} \mathrm{F}\right.$.). The correction shall be made by deducting from (when the temperature of gauging is above $15.5^{\circ} \mathrm{C}$.) or adding to (when the temperature of gauging is below $15.5^{\circ} \mathrm{C}$.) the gallonage as gauged. Such deduction or addition shall be computed on the basis of a coefficient of expansion of 0.000945 per degree centigrade (or 0.000525 per degree Fahrenheit). Example-If the temperature at which the spirits is gauged is $75^{\circ} \mathrm{F}$., and the volume delivered (at that temperature) is 8,000 gallons, then $0.000525 \times 15 \times 8$, o00 equals the quantity in gallons which must be subtracted from 8,000 gallons to give the true gallonage at $60^{\circ} \mathrm{F}$., or, if the temperature at which the spirits is gauged is $10^{\circ} \mathrm{C}$., then $0.000945 \times 5.5 \times 8,000$ equals the quantity in gallons which must be added to the gauged volume of 8,000 gallons to give the true gallonage at $15.5^{\circ} \mathrm{C}$.

(c) CERTIFICATION.-Mineral spirits delivered in barrels, drums, or tank cars shall either be accompanied by an official gauger's certificate showing the net contents of each container and also the temperature of contents at the time of gauging or shall be subject to gauging by the purchaser's inspector. In the absence of a statement of the temperature at the time of gauging on the official gauger's certificate, or in case the barrels show evidence of loss by leakage or other shortage, the delivery shall be subject to reinspection and regauging by the purchaser's inspector.

WASHINGTON, January 2, 1923. 